\title{
NÚMERos INTEIROS E DECIMAIS: UMA ABORDAGEM DOS CONTEÚdOS DE MATEMÁtICA POR MEIO DE UM JOGO FRENTE ÀS DIFICULDADES DO CENÁRIO TECNOLÓGICO DA EDUCAÇÃo BÁSICA
}

\author{
INTEGERS AND DECIMALS NUMBERS: AN APPROACH TO MATHEMATICS \\ CONTENTS THROUGH A GAME IN THE FACE OF THE DIFFICULTIES OF THE \\ TECHNOLOGICAL SCENE OF BASIC EDUCATION
}

DOI: http://dx.doi.org/10.23926/RPD.2526-2149.2018.v3.n2.p386-405.id231

\section{Fernando Francisco Pereira \\ Professor da Secretaria de Estado da Educação - PR. Mestrando em Ensino de Matemática (UTFPR). fernandoutfcp@gmail.com}

\section{Iara Souza Doneze}

Professora da Secretaria de Estado da Educação - PR. Mestranda em Ensino de Matemática (UTFPR). iaradoneze@gmail.com

\section{Luciano Tadeu} Esteves Pansanato Doutor em Ciências da Computação e Matemática Computacional.

Professor titular do departamento de computação (UTFPR).

luciano@utfpr.edu.br
Resumo: Com a intencionalidade de contribuir para pesquisas em Educação Matemática, ao delimitar o campo de estudos aos Números Inteiros e Decimais, esse artigo relata os resultados de uma proposta de promoção do uso das tecnologias no ensino de Matemática, que objetivou auxiliar os alunos na compreensão dos conteúdos de Números Inteiros - Decimais e suas operações. A proposta consistiu na adaptação e aplicação de um jogo de trilhas em formato digital, que utilizou o software Excel. Os participantes foram alunos entre 11 e 13 anos de idade, de uma escola pública do Paraná. Desse modo, houve três momentos: Pré-teste, Proposta e Pós-teste, fases essas que permitiram uma visão das compreensões dos estudantes a respeito do conteúdo, anterior e posterior à sua aplicação. Ao final, conclui-se que os discentes possuem consideráveis habilidades em relação ao emprego de algoritmos da adição de números inteiros e decimais, entretanto, no emprego da operação de subtração, no mesmo contexto, apresentaram consideráveis dificuldades que foram cuidadosamente sanadas após a aplicação da proposta.

Palavras-chave: Educação Matemática. Números Inteiros e Decimais. Educação Básica. Tecnologias.

\begin{abstract}
Seeking to contribute to research in Mathematics Education, delimiting the field of studies to the Whole and Decimal Numbers, here is presented the results of a proposal, to promote the use of technologies in Mathematics teaching, which aimed to help students in understanding the contents of Numbers Integer Decimals and their operations. The proposal consisted in the adaptation and application of a trail game in digital format, using Excel software. The participants were students between 11 and 13 years old, from a public school in Paraná. Happening in three moments: Pre-test, Proposal and Post-test, allowed a view of the students' understandings about the content, before and after the application of the proposal. At the end, it is concluded that the students have considerable abilities regarding the use of algorithms of the addition of integers and decimals, already in the use of the subtraction operation, in the same context, presented considerable difficulties, which were considerably remedied after the application of the proposal.
\end{abstract}

Keywords: Mathematical Education. Integers and Decimal Numbers. Basic Education. Technologies. 


\section{INTRODUÇÃO}

Quando se analisa o livro $O$ computador na sociedade do conhecimento de José Armando Valente, 1999, por meio do seu título, é possível refletir que, há quase duas décadas atrás, já se conjecturava uma sociedade imersa no uso das tecnologias, em especial, com a utilização do computador. Embora, não seja uma totalidade, esse objeto está em evidência nas casas, nos escritórios, nos comércios e nas escolas. Em outras palavras, esse aparato é uma realidade em todos os âmbitos que compõe a sociedade.

Por fazer parte da sociedade e estar a serviço dela, o computador, é concebido como um eficiente instrumento na solução de questões diárias, associado, em suma, a praticidade. Tal condição remete-se as ações presentes nas rotinas administrativas dos gestores e diretores das escolas, no entanto, se faz distante das rotinas de docentes e discentes em seu interior. Essa problemática, quando atrelada à importância do uso das tecnologias em sala de aula, fomenta pesquisas que buscam analisar e caracterizar tais fatos. Como resultado das constatações, surgem inúmeras possibilidades e/ou proposições que objetivam favorecer e incentivar seu uso efetivo pelos docentes no processo de ensino e aprendizagem.

Ao abordar o ambiente escolar, especificamente, o de ensino de Matemática, de um modo geral, esse sempre esteve e está envolto a mitos, crenças e ritos. Esses fatores, de modo amplo, estão ligados a experiências e concepções ascendentes, seja dos familiares ou até de professores, quando alunos (D’AMBRÓSIO, 1993; HOFFMANN, 1991; BARLOW, 2006). Nesse sentido, indo além dos aspectos infraestruturais, pesquisas buscam incentivar a promoção das tecnologias nas conduções das aulas dessa disciplina como forma de romper antigas concepções e estereótipos e de atrelar a materialização do conteúdo em forma de teoria à prática.

Construída nesse cenário, a proposta aqui apresentada, teve como objetivo principal auxiliar os alunos na compreensão dos conteúdos de Números Inteiros - Decimais e suas operações. Para que esse intuito pudesse ser alcançado, procurou-se: delimitar um conteúdo matemático específico, Números Inteiros e Decimais, dentro dos blocos de conteúdos disponibilizados pelos documentos oficiais, Números e Operações; adaptar uma atividade física, presente em um determinado livro didático a fim de ser aplicada como orientação de jogo, mediante ao uso de recursos tecnológicos; e analisar as produções escritas, não requeridas, mas, apresentadas pelos alunos em um rascunho.

\section{O QUE TRAZEM OS DOCUMENTOS OFICIAIS ACERCA DO USO DA INFORMÁTICA EM SALA DE} AULA 
No Brasil, até pouco tempo, quando o assunto era a educação, apresentavam-se como principais documentos oficiais, os Parâmetros Curriculares Nacionais - PCNEF (BRASIL, 1997a; 1998; 2000; 2002), as Orientações Curriculares para o Ensino Médio - OCME (BRASIL, 2006), e de modo geral, a Lei n ${ }^{\circ}$ 9.394/96 - Lei de Diretrizes e Bases da Educação - LDB (BRASIL, 1996). Recentemente, um novo documento enlaça os anteriores, a Base Nacional Comum Curricular - BNCC (BRASIL, 2017), esse material traz algumas referências ao emprego dos recursos tecnológicos na educação. Sabe-se, que a grande parte dos documentos oficiais supracitados, data de uma ou duas décadas atrás. Sendo assim, atentar-se para os anos de surgimento de cada documento é proposital, não no sentido de anular seus méritos, mas com o intuito de rever o que era abordado por eles, quase duas décadas atrás, quando o assunto é uso da informática no ambiente escolar, em comparação com a atual conjuntura da educação brasileira.

No final do século XX e início do século XXI, período em que surgiam os PCNs (BRASIL, 1997a, 1998, 2000, 2002), o país iniciava um momento de difusão da informática para a sociedade. Nesse período, havia um notório incentivo à pesquisa e trabalho com computadores nas universidades, redução dos impostos na compra de computadores pessoais, propagação do acesso aos provedores de internet em instituições e residências, além do incentivo de acesso a informática nas escolas públicas e cursos de capacitação à sociedade. De certa forma, tais atos influenciaram a elaboração dos PCNs na época, segundo as orientações dos mesmos no Ensino Fundamental (BRASIL, 1997a):

\begin{abstract}
Desde a construção dos primeiros computadores, na metade deste século, novas relações entre conhecimento e trabalho começaram a ser delineadas. Um de seus efeitos é a exigência de um reequacionamento do papel da educação no mundo contemporâneo, que coloca para a escola um horizonte mais amplo e diversificado [...] trata-se de ter em vista a formação dos estudantes em termos de sua capacitação para a aquisição e o desenvolvimento de novas competências, em função de novos saberes que se produzem e demandam um novo tipo de profissional, preparado para poder lidar com novas tecnologias e linguagens, capaz de responder a novos ritmos e processos (BRASIL, 1997a, p. 27-28).
\end{abstract}

Em sua elaboração, o PCN do Ensino Fundamental (BRASIL, 1997a, p. 67 - 68) considerou "indiscutível a necessidade crescente do uso de computadores pelos alunos, como instrumento de aprendizagem escolar, para que então pudessem estar atualizados e instrumentalizados em relação às novas tecnologias da informação e as demandas sociais presentes e futuras". Ao passo que se destacou a indiscutível inserção dos computadores no ambiente escolar, também transpareceu a preocupação com as condições das escolas públicas, "pois muitas não tinham sequer giz para trabalhar", o que exigia um "posicionamento e 
investimento em alternativas criativas para que as metas fossem atingidas" (BRASIL, 1997a, p. $67-68)$.

No Ensino Médio, o foco era em preparar e capacitar cientificamente os alunos para utilizar as diferentes tecnologias relativas às áreas de atuação. $\mathrm{Na}$ época, a denominada "revolução informática", permitiu afirmar que nas próximas décadas, a educação iria se transformar mais rapidamente em função de uma nova compreensão teórica sobre o papel da escola, estimulada pela incorporação das novas tecnologias. De fato, a incorporação das novas tecnologias na escola se faz necessário, pois permite contextualizar os conhecimentos de todas as áreas e disciplinas no mundo do trabalho (BRASIL, 2000; 2002; 2006).

Diante do contexto atual, a BNCC (BRASIL, 2017), salienta, principalmente, o uso de softwares e da internet como ferramenta de pesquisa e levantamento de dados a fim de fortalecer, ainda, a importância das mudanças e avanços da "cultura digital", na qual os estudantes estão diretamente inseridos como protagonistas:

[...] esse quadro impõe à escola desafios ao cumprimento do seu papel em relação à formação das novas gerações. É importante que a instituição escolar preserve seu compromisso de estimular a reflexão e a análise aprofundada e contribua para o desenvolvimento, no estudante, de uma atitude crítica em relação ao conteúdo e à multiplicidade de ofertas midiáticas e digitais. Ao aproveitar o potencial de comunicação do universo digital, a escola pode instituir novos modos de promover a aprendizagem, a interação e o compartilhamento de significados entre professores e estudantes (BRASIL, 2017, p. 59).

No que tange a educação básica como um todo, a LDB é concisa ao expressar que, de modo geral, os objetivos e as finalidades da formação dos educandos consistem na formação básica necessária para que o educando compreenda o ambiente natural, social, político e tecnológico que fundamenta a sociedade ao seu redor, no mesmo sentido que ocorra a preparação básica para o trabalho e a cidadania ao promover a continuidade dos estudos e adaptar-se com flexibilidade à novas condições de ocupações científicas e tecnológicas que presidem a produção moderna que tem como proposta associar a teoria com a prática (BRASIL, 1996, art. 32, art. 35, art. 35-A, art.36).

Diante de todo o cenário supracitado, nota-se que, nas últimas décadas, houve uma notória atenção governamental no que se refere ao incentivo e emprego de recursos tecnológicos voltados a educação, o que possibilitou a busca pela promoção de uma abordagem mais significativa em relação aos conceitos que formam as bases teóricas e a capacidade de exercitar na prática os conceitos anteriormente aprendidos. No entanto, segundo Lima, Souto e Kochhann (2017), mesmo integrando muitas experiências educacionais envolvendo as tecnologias, a realidade educacional frente a elas pouco mudou passado duas décadas da 
institucionalização dos PCNs. Dentro dessa perspectiva, faz-se necessário, no que tange as tecnologias, mais estudos nessa área, com a intencionalidade de suscitar nos professores o conhecimento de suas possibilidades e limitações diante do processo de ensino e aprendizagem.

\section{ReCursos digitais nas escolas públiCas: UM Panorama da EDUCAÇão básica BRASILEIRA FRENTE À PROMOÇÃO DO ACESSO A INFORMÁTICA NO AMBIENTE ESCOLAR}

De forma modesta, a inserção das tecnologias de informática no ambiente educacional brasileiro ocorreu em meados de 1970, quando, influenciados por projetos que aconteciam nos Estados Unidos e França, sem as mesmas possibilidades e pretensões, diversos educadores brasileiros participaram do I Seminário Nacional de Informática na Educação, o que propiciou o surgimento de programas como o Educom, Formar e Proninfe, antecessor do ProInfo. O Proninfe, cujo objetivo era a criação de laboratórios e centros para capacitar os professores frente à informática, tornou-se o propulsor do atual ProInfo (VALENTE, 1999; BORBA, PENTEADO, 2007, p. 20)

O ProInfo ou Programa Nacional de Informática na Educação, criado em 1997 e vigente, atualmente, está vinculado à Secretaria de Educação a Distância, cuja intenção é a implantação de Núcleos de Tecnologia Educacional com entrega de laboratórios com suporte técnicopedagógico e capacitação de pessoal especializado em Informática na Educação. Nesse viés, surge a implantação de laboratórios, TVs pendrive, Laptops e Tablets como incentivo à inserção das Tecnologias de Informação e Comunicação - TICs, no ambiente escolar (VALENTE, 1999).

Desse modo, é importante dar consideração às pesquisas como as de Leite e Ribeiro (2012) Carvalho e Monteiro (2012), Martins e Flores (2015), que se propuseram investigar as condições atuais dos objetos de implantação elaborados pelos governos ao visar o incentivo das TICs nas escolas. Tais pesquisas revelaram não só as condições ligadas à formação docente para as tecnologias, bem como, as estruturais, seja tanto em espaço físico quanto na depreciação material. Quase duas décadas atrás, Valente (1999) atentava-se à mudanças pedagógicas para inserção das tecnologias aliadas ao processo de ensino e aprendizagem, de tal modo que nas pesquisas de Leite e Ribeiro (2012), Carvalho e Monteiro (2012), Martins e Flores (2015), houve a constatação da falta de pessoal especializado ligado diretamente as tecnologias e, em específico, aos laboratórios, além de notarem, também, as condições físicas relacionadas a ausência de espaço próprio e/ou falta de manutenção, seja do espaço ou de suprimentos, que quando atrelados, culminam em laboratórios fechados. Essas dificuldades e desafios, em se 
instaurar mudanças, colaboram para o distanciamento ao acesso a recursos tecnológicos e a estagnação de práticas tradicionais de ensino, o que favorece o entrave em detrimento dos objetivos elencados pelos documentos oficiais.

Ao apresentar esse cenário, cabe ressalvar o esforço dos diversos profissionais da educação na busca em driblar as dificuldades e enfrentar os desafios. Nessa perspectiva, as contribuições feitas por Mercado (2002), Cipriani (2007), Mueller (2013) revelam os esforços de um todo ao sanar as dificuldades e promover a inserção das tecnologias no processo de ensino e aprendizagem, em especifico, nas aulas de Matemática da Educação Básica. No tocante do uso das tecnologias nas aulas de Matemática e da necessidade de superar os desafios da formação docente frente ao uso de tais recursos, destaca-se a pesquisa de Lima, Souto e Kochhann (2017) cuja finalidade consistiu em investigar quais e como as tecnologias digitais são utilizadas por professores na formação inicial de um curso de licenciatura em Matemática de uma universidade pública. Os pesquisadores perceberam as contribuições que o uso das tecnologias digitais suscita nos futuros professores a fim de que rompam com as ideias historicamente enraizadas de que a matemática é única, absoluta e exata, encorajando-os a utilizar os recursos tecnológicos dentro do ambiente escolar.

\section{O USO dos RECURSOS TECNOLÓgicos digitais EM RELAÇÃo AOS CONTEÚdos MATEMÁTICOS: UM OLHAR PARA O ENSINO DE NÚMEROS E OPERAÇÕES}

Ao analisar a relevância dos recursos tecnológicos no ambiente educativo, espera-se transformar as práticas enraizadas nos moldes tradicionais ao objetivar "fazer coisas novas e pedagogicamente importantes que não se pode realizar de outras maneiras" (MERCADO, 2002, p. 12) que não seja pela inclusão das tecnologias (CIPRIANI, 2007; LIMA, SOUTO, KOCHHANN, 2017). Tal transformação busca aproximar as tecnologias da ação docente com a pretensão de caminhar paralelamente aos conteúdos e competências de determinada disciplina, durante o processo de ensino e de aprendizagem. Nesse sentido, os PCN (BRASIL, 1998) apresentam alguns caminhos para se fazer Matemática. Longe de afirmar que há um direcionamento especifico e bem definido de se fazer Matemática, esse intenção refere-se ao sentido de conceber diversas possibilidades de trabalhar a Matemática em sala de aula, dentre as quais se encontram as tecnologias que ofertam não só entretenimento ou diversão, todavia, contextos e instrumentos que permitem, de forma interativa, construir, manipular e solucionar inúmeras situações problemas que permeiam o ambiente social no qual se está inserido (MUELLER, 2013). 
No que se refere à utilização das tecnologias, em especifico o computador, nas aulas de Matemática, os PCN (BRASIL, 1998, p.45) afirmam que podem contribuir para que “[...] o processo de ensino e aprendizagem de Matemática se torne uma atividade experimental mais rica, sem riscos de impedir o desenvolvimento do pensamento do aluno, [...] e sua capacidade crítica”. Em um contexto especifico, estritamente para esta discussão, o trabalho com os conteúdos de números inteiros - decimais e suas operações, pertencentes ao bloco de Números e Operações, de acordo com os PCNs (BRASIL, 1997b; BRASIL, 1998), com frequência, os alunos chegam ao final do Ensino Fundamental por meio de um "conhecimento insuficiente dos números, de como eles são utilizados e dos diferentes significados das operações", o que promove a dificuldade em interpretar os números obtidos e dar respostas a uma determinada situação problema (BRASIL, 1998, p. 95).

Quando se observa os contributos de Lopes, Wielewski, de Sá (2018) que se propuseram fazer um levantamento da produção acadêmica em teses e dissertações brasileiras sobre ensino e aprendizagem de números decimais no período de 1995 a 2015, identifica-se as corroborações de Borba e Santos (1997) e Nogueira e Signorini (2010).

O estudo de Borba e Santos (1997) compreende as dificuldades apresentadas pelos alunos dos anos iniciais do Ensino Fundamental frente aos problemas aditivos que envolvem os números decimais e o uso dos algoritmos das operações que enlaçam o conteúdo. No mesmo campo do estudo de Borba e Santos (1997), surgem às colaborações de Nogueira e Signorini (2010) que entrevistaram os alunos dos anos iniciais do Ensino Fundamental, buscando investigar se o ensino da aritmética, com ênfase nos algoritmos das operações fundamentais, favorece a construção do conhecimento matemático. Em ambas as pesquisas, foram apresentados, como resultados de suas analises, as dificuldades dos estudantes ao manipularem os algoritmos das operações de adição e subtração. Ao propor um olhar "Para além do Algoritmo", Nogueira e Signorini (2010, p. 265), ao entrevistarem os discentes, sugeriram que apresentassem as resoluções de uma operação a partir de estratégias desprendidas da utilização de algoritmos já tradicionalmente usado, incitando, por sua vez, a utilidade de cálculos mentais. Entretanto, suas verificações fortalecem resultados já supracitados; os alunos não são encorajados a apresentarem soluções quando estão desamparadas do uso de algoritmos.

Diante do cenário vivenciado em sua pesquisa, Nogueira e Signorini (2010) sustentam o incentivo de cálculos classificados como mentais no desenvolvimento da autonomia para a cidadania. Seus estudos afirmam que: 
Não existe conteúdo específico de Matemática para a cidadania, todavia, quando a criança é capaz de efetuar cálculos mentais e ter confiança nos resultados obtidos, ela está exercendo sua cidadania "matemática". É com discussões e troca de ideias que a criança vai desenvolvendo sua autoconfiança, fator indispensável para que ela se aventure em experiências matemáticas fora do contexto escolar (NOGUEIRA; SIGNORINI, 2010, p. 267).

Dentro desse contexto, ao enlaçar os contributos de Borba e Santos (1997) e Nogueira e Signorini (2010), o ensino dos conteúdos do bloco de Números e Operações segundo o PCN:

[...] deve privilegiar atividades que possibilitem ampliar o sentido numérico e a compreensão do significado das operações, ou seja, atividades que permitam estabelecer e reconhecer relações entre os diferentes tipos de números e entres as diferentes operações (BRASIL, 1998, p. 95)

De acordo com o próprio documento, no trabalho com os números e operações, é importante e fundamental desenvolver o trabalho com cálculos que envolva diferentes tipos de números e operações em situações problemas, como por exemplo, circunstâncias em que envolva "uma noção intuitiva dos números negativos que emerge de experiências práticas, como perder no jogo, constatar saldos negativos, situação de compra em um supermercado, saber qual é o saldo ou o débito em uma conta bancária” (BRASIL, 1998, p. 98). Essas conjunturas, muitas vezes envolvem cálculos exatos paralelamente ligados a cálculos mentais e/ou escritos, o que requisita aos alunos procurem aperfeiçoar seus procedimentos pessoais, tornando os cada vez mais práticos. Sendo assim, é no sentido de praticidade na realização de cálculos que se recomenda o trabalho com computadores e calculadoras:

No mundo atual saber fazer cálculos com lápis e papel é uma competência de importância relativa e que deve conviver com outras modalidades de cálculo, como o cálculo mental, as estimativas e o cálculo produzido pelas calculadoras, portanto, não se pode privar as pessoas de um conhecimento que é útil em suas vidas (BRASIL, 1998, p. 45, grifo nosso).

Dessa forma, o uso das ferramentas tecnológicas corrobora, significativamente, para o processo de ensino e de aprendizagem de Matemática ao tornar uma atividade experimental de associação à situações que valorizem e incorporem a tecnologia a práticas sociais atuais.

\section{CARACTERIZANDO OS MATERIAIS E MÉTODOS}

Nesse momento, cabe salientar, que embora os materiais e métodos utilizados na coleta de dados aparentam-se quantitativos, devido ao uso de questionários com alternativas de múltipla escolha e quadros que relatam os acertos e erros dos alunos participantes, procurou-se embasar a análise e as discussões, tendo como foco as produções ou registros elaborados pelos alunos, no rascunho, no decorrer da atividade, permitindo assim ressaltar o caráter qualitativo por trás de cada resposta, o que de acordo com Bogdan e Biklen (1994) apresentam-se como 
uma tentativa para a compreensão mais detalhada dos significados e características situacionais pensados pelos sujeitos pesquisados.

Com o objetivo de evidenciar quem são os sujeitos participantes, a proposta e o ambiente em que a pesquisa foi desenvolvida, faz-se necessário uma caracterização individual do(a): local de pesquisa; proposta de ensino; momentos de aplicação.

\subsection{CARACTERIZANDo OS SUJEITOS E O AMBIENTE}

Os sujeitos desse estudo consistem em 7 (sete) alunos com idade entre 11 e 13 anos, matriculados regularmente nos anos finais do Ensino Fundamental. No entanto, a proposta ocorreu em uma Sala de apoio à Aprendizagem de Matemática. Essa configuração de sala consiste em uma ação criada pela Secretaria do Estado de Educação do Paraná - SEED PR por meio da Resolução Secretarial n. 371/2008 e a Instrução normativa n.022/2008, posteriormente atualizada pela Resolução Secretarial n. 2772/2011 e a Instrução normativa n. 007/2011. Segundo essas resoluções e instruções normativas, a sala de apoio à aprendizagem tem por objetivo auxiliar os alunos dos anos finais do Ensino Fundamental a sanarem as dificuldades apresentadas no decorrer das aulas no período regular.

Em relação à ação docente nas salas de apoio a aprendizagem, a SEED PR por meio das normativas (Instrução normativa n.022/2008, n. 007/2011) exprime à necessidade de práticas voltadas a promoção de metodologias diferenciadas das realizadas no ensino regular, de tal modo, que tais ações educativas permitam atingir as necessidades individuais de cada aluno. Nas normativas instituídas pela SEED PR, há uma especificação quanto à quantidade de estudantes matriculados por sala de apoio, contudo, não deixam claras as divisões por séries, fazendo com que grande parte das escolas que já apresentam falta de infraestrutura coloque os discentes de diversas séries em uma mesma sala de apoio a aprendizagem, o que impulsiona o surgimento de salas multisseriadas. O cenário posto acima justifica não só os sujeitos apresentarem idade entre 11 e 13 anos, mas, sobretudo, a importância de propostas pedagógicas distintas das tradicionais.

\subsection{Caracterizando a Proposta}

A proposta de intervenção consistiu em um jogo denominado Saldo e Débito. O mesmo foi desenvolvido no software Excel, oriundo do pacote Microsoft Office 2011. Essa nomenclatura é uma adaptação do jogo de trilha homônimo, presente no livro Caminhar e transformar - Matemática: Anos Finais do Ensino Fundamental de Eduardo Afonso de Medeiros Parente (PNLD EJA 2014/2016). 
A Figura 1 trata-se da proposição física e inicial de jogo presente no livro de Eduardo Parente para os anos finais do Ensino Fundamental.

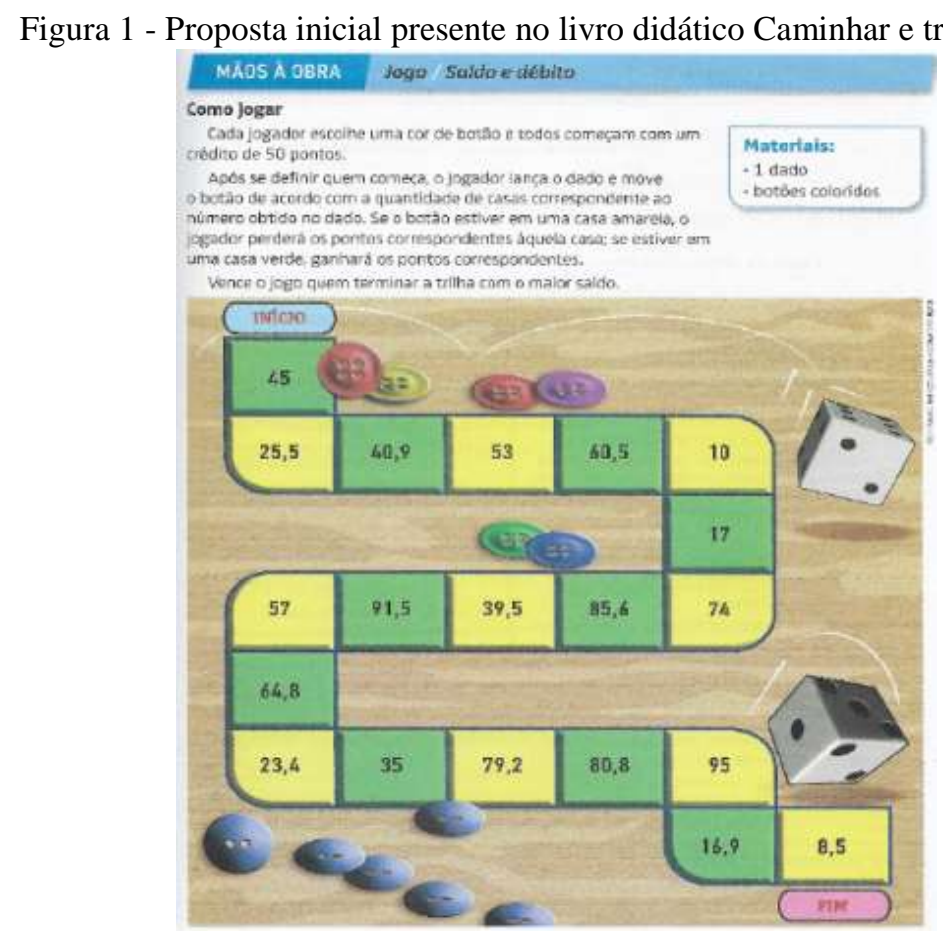

Fonte: Livro Caminhar e transformar (PARENTE, 2013).

Por meio da ação educativa apresentada no livro (Figura 1), procurou-se criar uma proposta $^{1}$ que permitisse atrelar o conteúdo e os objetivos da orientação original a uma que possibilitasse abordar o uso da tecnologia, o computador, bem como algumas de suas funcionalidades, além de despertar o interesse por parte dos alunos, devido à ludicidade desse aparato.

Figura 2 - Proposta adaptada para o uso do computador no Ensino de Matemática.

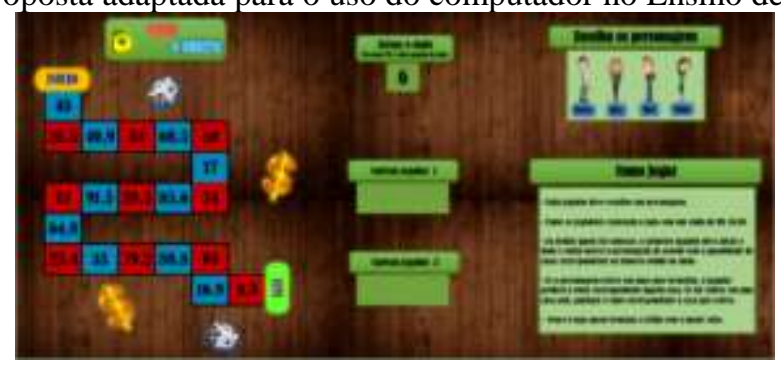

Fonte: Dos autores (2018) adaptado de Parente (2013).

A Figura 2 apresenta, de fato, a adaptação do jogo elaborado para o Excel, o que permitiu, além de todas as possibilidades que a original possuía, que o mesmo fosse editado, ter sua trilha aumentada ou reduzida, o acréscimo de personagens e, o principal, o uso das funcionalidades do Excel, bem como, na célula Carteira do Jogador, efetuar cálculos por meio

\footnotetext{
${ }^{1}$ A proposta está disponível gratuitamente para livre utilização e edição através do link: https://goo.gl/Y6odRk 
de funções simples do Excel, como por exemplo $=45+25,5$ ou $=B 5+B 6$, ou até, com o dado digital do jogo, a função =ALEATÓRIOENTRE $(1 ; 6)$.

Seu emprego em sala de aula consistiu, inicialmente, em solicitar que os alunos formassem 2 (dois) grupos, um com 4 (quatro) integrantes e outro com 3 (três). Cabe ressalvar que estar no corpo de texto um breve panorama do cenário escolar brasileiro frente aos recursos tecnológicos é proposital, visto que a escola apresenta um laboratório de informática, porém, o mesmo encontra-se fechado e sem condições de utilização, devido à ausência de manutenção e reposição de equipamentos. Como alternativa, o professor, e também, um dos autores deste trabalho, disponibilizou um notebook de uso pessoal para que os estudantes, dispostos em grupos, pudessem realizar a atividade proposta.

A Figura 3 exemplifica parte do ambiente e como os alunos foram organizados para a realização da proposta.

Figura 3 - Primeiro grupo, recebendo as instruções do professor e se ambientando com a proposta.

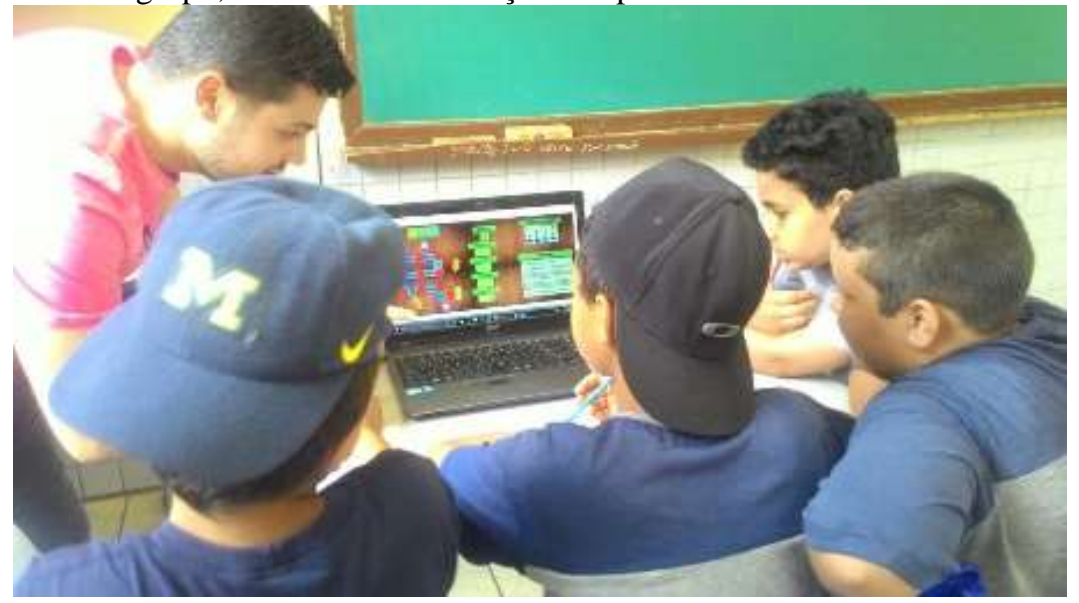

Fonte: Dos autores (2018).

Todos os cálculos deveriam ser realizados manualmente, registrados em um caderno, para que, posteriormente, pudessem ser comparados. Ao término da primeira rodada, uma nova se repetia, todavia, dessa vez, os cálculos deveriam ser realizados com o apoio da calculadora do software Excel, por meio do comando =, inserido na célula Carteira do Jogador. Já a segunda rodada tinha o objetivo de possibilitar uma comparação entre os resultados obtidos no software e os apontados no caderno.

\subsection{Caracterizando OS MOMENTOS}

O primeiro, denominado Pré-teste, consistiu na aplicação de uma lista de exercícios que envolveram operações com números negativos e positivos, decimais e/ou inteiros. A lista era composta por 3 (três) questões de múltipla escolha, com 4 (quatro) alternativas (a, b, c, d), sendo 
apenas uma correta. Seu intuito era obter e analisar os conhecimentos prévios dos alunos, antes da aplicação da proposta de intervenção com o jogo Saldo e Débito. O mesmo teve uma duração de 2 horas/aula.

Em um segundo momento, nomeado de o Jogo Saldo e Débito, que se fundamenta na apresentação das instruções e na condução do jogo. Nele os discentes iniciavam com um valor de 100 pontos que poderia ser alterado se adicionada ou subtraída a quantidade correspondente da "casa" na qual se encontrava na trilha. A aplicação teve uma duração de 2 horas/aula e, consequentemente, possibilitou o terceiro momento.

O terceiro momento, com a denominação Pós-teste, compõe-se de uma lista de exercícios, correlatos aos aplicados no Pré-teste, com questões de múltipla escolha e com 4 (quatro) alternativas (a, b, c, d) com a intencionalidade de analisar as contribuições acrescidas ao conhecimento dos alunos após a intervenção feita com o jogo Saldo e Débito.

\section{Alguns Resultados}

Para que fosse possível a apresentação e a discussão dos resultados obtidos na pesquisa, é necessária uma demonstração em dois momentos, partindo, de acordo, com as etapas que conduziram a coleta de dados.

\subsection{APliCAÇÃo E ANÁlise dos Resultados ANTES da EFETIVAÇÃO da PROPOSTA - PRÉ-TeSTe}

Com a divisão da análise em dois momentos referentes ao Pré-teste e o Pós-teste, o Quadro 1 revela o resultado dos alunos que assinalaram as alternativas corretas em cada uma das 3 (três) questões do Pré-teste.

Quadro 1 - Gabarito do Pré-teste: questões e alunos que marcaram a alternativa certa

\begin{tabular}{|c|c|c|c|c|c|c|c|}
\hline Questão $\quad$ Aluno & A1 & $\mathrm{A} 2$ & A3 & A4 & A5 & A6 & A7 \\
\hline Questão 1 & $x$ & $X$ & $X$ & $X$ & $x$ & $X$ & $X$ \\
\hline Questão 2 & $\mathrm{X}$ & $X$ & $X$ & $X$ & $\mathrm{X}$ & $X$ & $X$ \\
\hline Questão 3 & & & & $x$ & & & \\
\hline
\end{tabular}

Fonte: Dos autores (2018).

O primeiro item abordado no Pré-teste: Qual das alternativas abaixo representa o resultado correto da adição: $50+45$
(a) 75
(b) 15
(c) 95
(d) 5 
Todos os 7 (sete) estudantes responderam a alternativa correta, (c) 95. Alguns deles se viram na necessidade de expressarem os cálculos que efetuaram para que fosse possível assinalar a alternativa em questão (alunos A1, A5, A2, A7, A4).

Figura 4 - Produções dos alunos A1, A5, A2, A7, A4 na primeira questão do Pré-teste

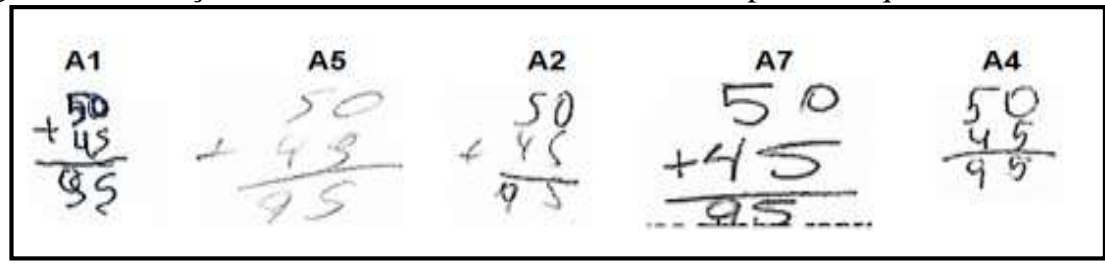

Fonte: Dos autores (2018)

As produções (Figura 4) nos permitem afirmar que os discentes compreendem e possuem certas habilidades em relação a efetuar cálculos, que envolvem números inteiros e a operação de adição. Todos usaram o mesmo algoritmo (arme e efetue), respeitando as posições das unidades e das dezenas.

No segundo ponto: Qual das alternativas abaixo representa o resultado correto da adição: $50+40,9$
(a) 10,1
(b) 90,9
(c) 90
(d) 80,1

Todos os 7 (sete) alunos responderam a alternativa correta (b) 90,9, dentro desse contexto, alguns deles, também, viram-se na necessidade de expressarem os cálculos que efetuaram para que fosse possível assinalar a alternativa adequada (alunos A1, A2, A3, A4, A7).

Figura 5 - Produções dos alunos A1, A2, A3, A4, A7 na segunda questão do Pré-teste

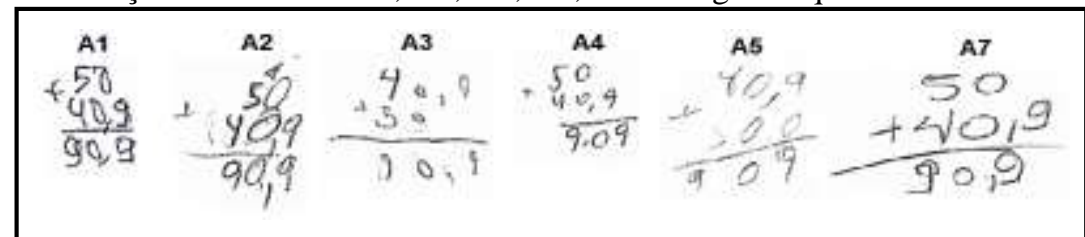

Fonte: Dos autores (2018)

As produções (Figura 5), assim como as efetuadas na questão anterior (Figura 4), revelam em relação ao trabalho com a operação de adição, que os alunos conseguem empregar corretamente o principal algoritmo da adição (arme e efetue / sobe 1). Vale atentar que em todos os registros (Figura 5), os mesmos revelaram conhecimentos mediante o posicionamento dos algarismos no que se refere ao sistema de posicionamento decimal. Embora os resultados sejam positivos, Nogueira e Signorini (2010) apontam que a principal dificuldade ao utilizar esse algoritmo está na falta de compreensão do valor posicional frente ao Sistema de Numeração 
Decimal, além da falta de entendimento dos conceitos por trás de cada ação que envolve o algoritmo da adição.

Na última questão do Pré-teste: Qual das alternativas abaixo representa o resultado correto da subtração: 50 - 25,5
(a) 25
(b) 20,5
(c) 24,5
(d) 75,5

Dos 7 (sete) partícipes da pesquisa, somente 1 (um), o A4, assinalou a alternativa que correspondia ao resultado correto da expressão 50 - 25,5, alternativa (c) 24,5.

Figura 6 - Produções dos alunos A1, A2, A3, A4, A5, A6, A7 na terceira questão do Pré-teste

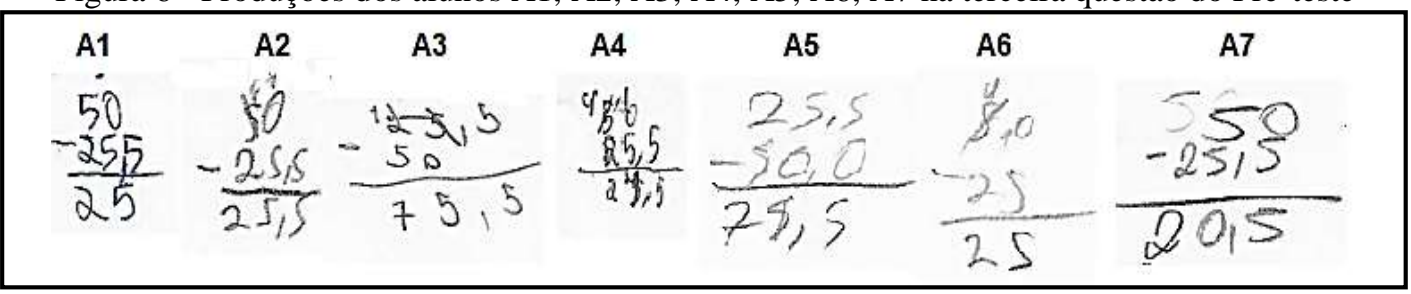

Fonte: Dos autores (2018)

Cabe observar cuidadosamente a (Figura 6) produção dos 7 (sete) alunos que sentiram a necessidade de mostrar seus cálculos. Ao ser o único a assinalar a alternativa certa, voltou-se os olhos a produção de A4 (Figura 6), nela, nota-se que o discente apresenta dificuldades ao trabalhar com o algoritmo (arme e efetue / emprestar) na operação de subtração, ocasionando seu erro em estabelecer o resultado correto, no entanto, supõe-se que por aproximação de valores, ele assinala a alternativa correta, (c) 24,5. A mesma confusão estabelecida por A4 (Figura 6) é aparente no aluno A2, entretanto, A3 e A5 demonstraram não interpretar corretamente a expressão 50 - 25,5, como uma subtração a ser feita e procederam com a adição, obtendo como resultado o distrator, 75,5 , alternativa (d).

Em todos os registros, nota-se que os alunos, no que se refere à operação de subtração, evidenciaram que não consideram os valores decimais, se observado ao sistema posicional, o ignorando ao trabalhar com o algoritmo da subtração. As dificuldades, enfatizadas acima, sustentam as proposições apresentadas por Nogueira e Signorini (2010); para as pesquisadoras as dificuldades frente ao algoritmo estão na memorização da ação de "emprestar um" sem saber ao certo seu valor posicional no algoritmo.

\subsection{APliCAÇão E ANÁlise dos RESUltados dePOIS da APLICAÇÃo da PROPOSTA - Pós- TESTE}

Assim como no Pré-teste, as questões abordadas no Pós-teste foram classificadas como fechadas, que por sua vez, apresentam-se com exercícios de algoritmo. 
O quadro 2 expõe o resultado dos alunos que assinalaram as alternativas corretas em cada uma das 3 (três) questões do Pós-teste.

Quadro 2 - Gabarito do Pós-teste: questões e alunos que assinalaram a alternativa correta

\begin{tabular}{|c|c|c|c|c|c|c|c|}
\hline Questão Aluno & A1 & A2 & A3 & A4 & A5 & A6 & A7 \\
\hline Questão 1 & $\mathrm{X}$ & $\mathrm{X}$ & $\mathrm{X}$ & $\mathrm{X}$ & $\mathrm{X}$ & $\mathrm{X}$ & $\mathrm{X}$ \\
\hline Questão 2 & $\mathrm{X}$ & $\mathrm{X}$ & $\mathrm{X}$ & $\mathrm{X}$ & $\mathrm{X}$ & $\mathrm{X}$ & $\mathrm{X}$ \\
\hline Questão 3 & $\mathrm{X}$ & $\mathrm{X}$ & & $\mathrm{X}$ & $\mathrm{X}$ & $\mathrm{X}$ & $\mathrm{X}$ \\
\hline
\end{tabular}

Fonte: Dos autores (2018)

A primeira questão abordada no Pós-teste: Qual das alternativas abaixo representa o resultado correto da adição: $53+74$
(a) 71
(b) 127
(c) 157
(d) 21

Todos os 7 (sete) alunos assinalaram a alternativa correta, (b) 127, da mesma forma, viram-se na importância de expressar seus cálculos.

Figura 7 - Produções dos alunos A1, A2, A3, A4, A5, A6, A7 na primeira questão do Pós-teste

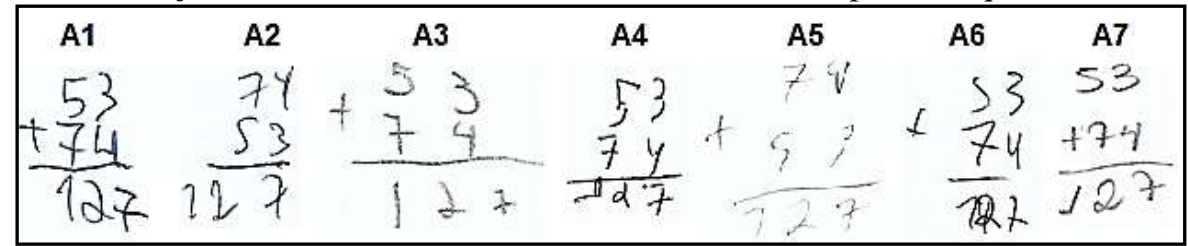

Fonte: Dos autores (2018)

Assim como no exercício correlato apresentado no Pré-teste, as produções (Figura 7) nos permitem consolidar a ideia de que os alunos, de fato, compreendem e dominam o algoritmo (arme e efetue) da operação de adição, mostrando possuírem habilidades em relação a efetuar cálculos que envolvem números inteiros e a operação de adição.

$\mathrm{Na}$ segunda questão: Qual das alternativas abaixo representa o resultado correto da adição: $73,4+8,5$
(a) 81,9
(b) 158,4
(c) 90,9
(d) 80,1

Todos os 7 (sete) alunos responderam a alternativa correta (a) 81,9, sendo que alguns deles expressaram os cálculos que efetuaram para que fosse possível assinalar a alternativa em questão (alunos A1, A3, A4, A5, A7). 
Figura 8 - Produções dos alunos A1, A3, A4, A5, A7 na segunda questão do Pós-teste

\begin{tabular}{|ccccc|}
\hline A1 & A3 & A4 & A5 & A7 \\
73,4 & +34 & 734 \\
$+8,5$ & $+8,5$ & 73,4 & 73,4 \\
81,5 & 81,9 & $\frac{715}{81,9}$
\end{tabular}$+\frac{08,5}{87,9} \frac{+8,5}{81,99}$

Fonte: Dos autores (2018)

A segunda questão do Pós-teste, diferiu-se de sua correlata no Pré-teste, em virtude de apresentar a adição de dois valores decimais. Ressalva-se que nesse momento, os alunos vão além e expressam não só habilidades quanto ao emprego do algoritmo da adição (arme e efetue / sobe 1), mas também em relação ao posicionamento decimal, como se pode observar (Figura 8). Todos os alunos, no que se refere à operação de adição, consideraram e operaram com os valores decimais, não cogitando apenas os valores inteiros, as unidades e dezenas.

$\mathrm{Na}$ última questão: Qual das alternativas abaixo representa o resultado correto da subtração: 50 - 25,5
(a) 25
(b) 20,5
(c) 24,5
(d) 75,5

Por fim, procurou-se ressaltar, como na última questão do Pós-teste, a mesma dificuldade apresentada anteriormente no Pré-teste. O motivo consistiu que dos 7 (sete) alunos participantes da pesquisa, apenas 1 (um), o A4, havia assinalado a alternativa que correspondia ao resultado correto da expressão 50 - 25,5, alternativa (c) 24,5, no Pré-teste. No entanto, o Pós-teste apresentou resultados opostos e satisfatórios, ao passo que dos 7 (sete) alunos participantes, 6 (seis) assinalaram a alternativa que correspondia ao resultado correto, agora no Pós-teste, alternativa (a) 24,5.

Figura 9 - Produções dos alunos A1, A3, A4, A5, A7 na terceira questão do Pós-teste.

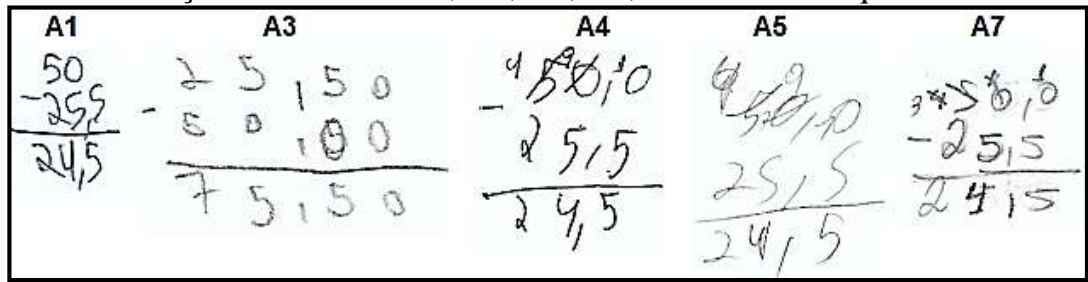

Fonte: dos autores (2018)

Com os resultados enfatizados na questão anterior (Figura 8), nota-se que, os alunos A1, A4, A5 e A7 (Figura 9), mostraram possuir habilidades quanto a operar o algoritmo da subtração (arme e efetue / emprestar), como também, nessa operação (subtração), não apenas os valores inteiros, as unidades e dezenas, mas, os decimais, passaram a ser considerados. Essa ação contornou as dificuldades anteriormente constatadas na mesma questão presente no Pré- 
teste. Nota-se que somente o aluno A3 (Figura 8) permaneceu com dificuldades quanto ao trabalho com os valores decimais, essa observação vai ao encontro da constatação feita por Borba () ao identificar que parte das dificuldades dos alunos no algoritmo da subtração, concentra-se na incompreensão da reserva e troca de termos, minuendo e subtraendo.

Porém, é necessário destacar, que o mesmo apresentou avanços em relação a sua produção anterior (Figura 6), ao expressar em seu algoritmo, os valores decimais que completavam tanto o minuendo, quanto o subtraendo.

Figura 10 - Afirmação feita pelo aluno A6 na terceira questão do Pós-teste

esre Resultodo tive no jegese

Fonte: dos autores (2018)

A afirmação supracitada (Figura 10), do aluno A6, vai ao encontro das afirmações de Brasil (1998, p. 98) anteriormente citadas, ao refletir a importância da proposta apresentada no jogo Saldo e Débito, como uma situação em que envolva "uma noção intuitiva dos números negativos que emerge de experiências práticas, como perder no jogo, constatar saldos negativos, situação de compra", condição essa que tem relação com cálculos exatos paralelamente ligados aos mentais e/ou escritos, o que faz requisitar que os alunos procurem aperfeiçoar seus procedimentos pessoais, tornando os cada vez mais práticos ao recomendar-se o trabalho com computadores e calculadoras.

\section{CONSIDERAÇÕES}

$\mathrm{Na}$ busca em tecer algumas considerações em detrimento da aplicação da proposta, no que se refere aos resultados dos alunos, considera-se que o objetivo principal, auxiliar os alunos na compreensão dos conteúdos de Números Inteiros - Decimais e suas operações, tenha sido atingido.

Em relação às operações, constatou-se o que também ficou evidente na pesquisa de Borba e Santos (1997), os alunos apresentaram maiores habilidades com a operação de adição do que a operação de subtração frente a valores decimais. O principal motivo, possível de constatar, está no algoritmo utilizado por eles (arme e efetue / emprestar). Ao empregar tal algoritmo, os alunos passaram a desconsiderar os valores decimais e foram impulsionados pelos distratores presentes nas alternativas, consequentemente, acabaram cometendo erros.

Outro aspecto a se destacar, é que os alunos por apresentarem dificuldades de interpretação do Sistema de Numeração Decimal (BORBA; SANTOS, 1997; NOGUEIRA; SIGNORINI, 2010), acrescentam unidades inexistentes ou deixam de acrescentar as unidades 
existentes. Dentro desse contexto, ao empregar e requisitar cálculos com valores inteiros e decimais, o jogo Saldo e Débito, possibilitou no Pós-teste que apresentassem resultados mais significativos, passando a considerar e empregar os valores decimais ao efetuarem os cálculos por meio do mesmo algoritmo utilizado, anteriormente (arme e efetue / emprestar).

É também essencial destacar o uso do computador em sala de aula e o emprego do software na obtenção dos cálculos. Ao passo que os alunos compreenderam e passaram utilizar a calculadora do próprio software, a partir do comando "=" digitado na célula da planilha, esses iniciaram um processo de comparação com os cálculos anteriormente registrados no rascunho e, então, observaram suas dificuldades e erros cometidos, o que favoreceu uma retomada dos cálculos. Desse modo, o uso do computador representado pelo jogo, permitiu aos alunos se apropriarem de uma autoavaliação como decorrência de uma autorreflexão elaborada sobre suas produções, certas ou erradas.

Por fim, pode-se concluir que há uma grande dificuldade em empregar o uso das tecnologias no ambiente escolar, em especifico, o computador, devido a falta de manutenção ou ausência de ambientes propícios, como os laboratórios de informática como já foi constatado por Leite e Ribeiro (2012), Carvalho e Monteiro (2012), Martins e Flores (2015). Dentro das limitações, faz-se necessário a tomada de ações positivas, seja no emprego de atividades em grupo e/ou na procura de ambientes externos ao escolar que permitam tal abordagem.

Assim, o primordial, consiste em diante das dificuldades apresentadas, propor mudanças a determinadas estagnações presentes no contexto educacional como sustenta Mercado (2002), Cipriani (2007) e Mueller (2013). Em geral, considera-se satisfatório no que se refere a contribuição para o campo da Educação Matemática, delimitado à promoção do uso das tecnologias no processo de ensino e de aprendizagem de conteúdos de Matemáticos. Acreditase que, embora tenha se fundamentado sobre uma proposta elementar, a exposição da motivação tanto do professor quanto dos alunos em, mesmo diante das dificuldades, fazer uso dos recursos tecnológicos disponíveis em prol do ensino e da aprendizagem, tenha significativa contribuição para o campo das pesquisas, em especifico, o uso das tecnologias para o ensino de conteúdos de Matemática, particularmente, dos Números Inteiros - Decimais e suas operações.

\section{REFERÊNCIAS}

BARLOW, M. Avaliação escolar - mitos e realidades. Porto Alegre: Artmed, 2006.

BOGDAN, R. C.; BIKLEN, S. K. Investigação qualitativa em educação: uma introdução à teoria e aos métodos. Portugal: Porto, 1994. 
BORBA, M. de C. PENTEADO, M. G. Informática e Educação Matemática. $3^{\text {a }}$ ed. Belo Horizonte: Autêntica, 2007.

BORBA, R. E. de S. R.; SANTOS, R. B. Investigando a resolução de problemas de estruturas aditivas por crianças de $3^{\mathrm{a}}$ série. Tópicos Educacionais, Recife, v. 15, n. 1-3, 1999. Disponível em: < https://goo.gl/eceni4> Acessado em: 15 out. 2018

BRASIL. Ministério de Educação e Cultura. LDB - Lei n 9394/96, de 20 de dezembro de 1996. Estabelece as diretrizes e bases da Educação Nacional. Brasília: MEC, 1996.

BRASIL. Parâmetros curriculares nacionais: introdução aos parâmetros curriculares nacionais. Secretaria de Educação Fundamental. Brasília: MEC/SEF, 1997a.

BRASIL. Parâmetros curriculares nacionais: matemática. Secretaria de Educação Fundamental. Brasília: MEC/SEF, 1997b.

BRASIL. Parâmetros curriculares nacionais: matemática. Secretaria de Educação Fundamental. Brasília: MEC/SEF, 1998.

BRASIL. Parâmetros curriculares nacionais: Ciências da Natureza, Matemática e suas Tecnologias. Brasília: MEC/SEMTEC, 2000.

BRASIL. Parâmetros curriculares nacionais: Ciências da Natureza, Matemática e suas Tecnologias - Orientações Educacionais Complementares. Brasília: MEC/SEMTEC, 2002.

BRASIL. Orientações curriculares para o ensino médio: matemática. Secretaria de Educação Básica. Brasília: MEC/SEB, 2006.

BRASIL. Base Nacional Comum Curricular - Educação é a base. Brasília: MEC, 2017.

CARVALHO, L. M. T. L.; MONTEIRO, C. E. F. Reflexões sobre implantação e uso de laboratórios de informática na escola pública. Roteiro, Joaçaba, v. 37, n. 2, p. 343 - 360, 2012. Disponível em: < https://goo.gl/YW6JHA>. Acessado em: 15 dez. 2018

CIPRIANI, O. N. Construindo um Jogo Para Uso na Educação Matemática. 2007. 53 f. Monografia (Graduação) - Departamento de Ciências da Computação, Universidade Federal de Lavras, Lavras, 2007.

D’AMBROSIO, B. Formação de professores de Matemática para o século XXI: o grande desafio. São Paulo, Pro-posições, vol 4 n. 1 (10), mar. 1993, p. 35 - 41.

LEITE, W. S.; RIBEIRO, C. A. do N. A inclusão das TICs na educação brasileira: problemas e desafios. Revista Intercional de Investigación en Educación, Bogotá, v. 5, n. 10, p. 173 187, 2012. Disponível em: 〈https://goo.gl/7sUUZU〉. Acessado em: 14 dez. 2018

LIMA, V. S. A.; SOUTO, D. L. P.; KOCHHANN, M. E. R. Tecnologias Digitais no Ensino Superior: um Zoom. Revista Prática Docente, Confresa, v. 2, n. 2, p. 138 - 157, 2018.

LOPES, T. B.; WIELEWSKI, G. D.; DE SÁ, P. F. Levantamento da produção acadêmica em teses e dissertações brasileiras sobre ensino e aprendizagem de números decimais no período 
de 1995 a 2015. REnCiMa, v. 9, n. 4, p. 110-125, 2018. Disponível em: https://goo.gl/VqbJja> Acessado em: 15 out. 2018

MARTINS, R. X.; FLORES, V. de F. A implantação do Programa Nacional de Tecnologia Educacional (ProInfo): revelações de pesquisas realizadas no Brasil entre 2007 e 2011. Revista Brasileira de Estudos Pedagógicos, Brasília, v. 96, n. 242, p.112-128, 2015. Disponível em: < https://goo.gl/944vVU>. Acessado em: 15 dez. 2018

MERCADO, L. P. L. Novas Tecnologias na Educação: Reflexões sobre a Prática. Maceió: EDUFAL, 2002.

MUELLER, L. C. Uso de recursos computacionais nas aulas de Matemática. 2013. $117 \mathrm{f}$. Dissertação (Mestrado) - Mestrado Profissional em Ensino de Ciências Exatas, Centro Universitário Univates, Lajeado, 2013.

NOGUEIRA, C. M. I.; SIGNORINI, M. B. Crianças, algoritmos e o sistema de numeração decimal. Investigações em Ensino de Ciências, v. 15, n. 2, p. 259-274, 2016. Disponível em: < https://goo.gl/WPKJ8T> Acessado em: 15 out. 2018

VALENTE, J. A. O computador na sociedade do conhecimento. Campinas: UNICAMP/NIED, 1999.

Recebido em: 16 de julho de 2018 Aprovado em: 28 de outubro de 2018. 